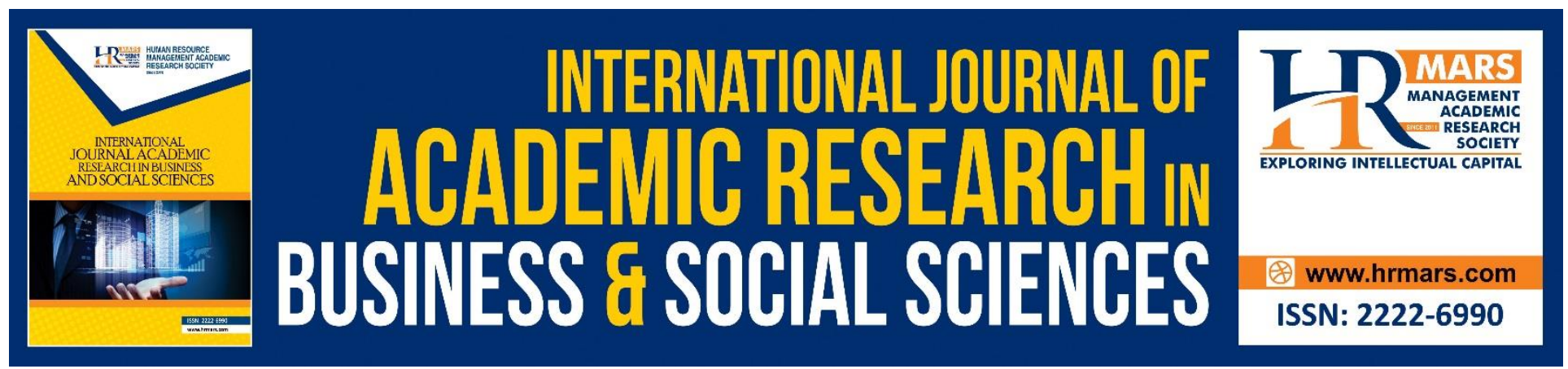

\title{
Manufacturing Convergence of ASEAN: Too Good to Be True?
}

\section{A. M Dayang Affizzah, Mohd Khairul Hisyam H., Haslan O.}

To Link this Article: http://dx.doi.org/10.6007/IJARBSS/v11-i14/8568

DOI:10.6007/IJARBSS/v11-i14/8568

Received: 09 December 2020, Revised: 07 January 2020, Accepted: 15 January 2020

Published Online: 27 January 2020

In-Text Citation: (Affizzah et al., 2021)

To Cite this Article: Affizzah, A. M. D., Hisyam, M. K. H., \& Haslan, O. (2021). Manufacturing Convergence of ASEAN: Too Good to Be True? International Journal of Academic Research in Business and Social Sciences, 11(14), 211-221.

Copyright: (C) 2021 The Author(s)

Published by Human Resource Management Academic Research Society (www.hrmars.com)

This article is published under the Creative Commons Attribution (CC BY 4.0) license. Anyone may reproduce, distribute, translate and create derivative works of this article (for both commercial and non-commercial purposes), subject to full attribution to the original publication and authors. The full terms of this license may be seen

at: http://creativecommons.org/licences/by/4.0/legalcode

Special Issue: Contemporary Business and Humanities Landscape Towards Sustainability, 2021, Pg. 211 - 221

http://hrmars.com/index.php/pages/detail/IJARBSS

JOURNAL HOMEPAGE

Full Terms \& Conditions of access and use can be found at http://hrmars.com/index.php/pages/detail/publication-ethics 


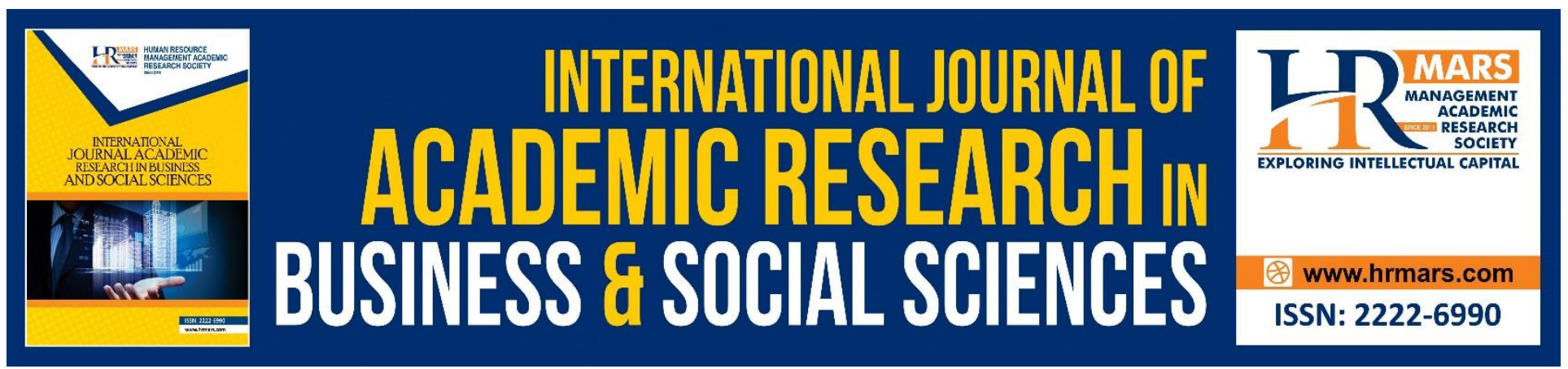

\title{
Manufacturing Convergence of ASEAN: Too Good to Be True?
}

\author{
A. M Dayang Affizzah, Mohd Khairul Hisyam H., Haslan O. \\ Faculty of Economics and Business, Universiti Malaysia Sarawak, Kota Samarahan, Sarawak \\ Email: amdaffizah@unimas.my
}

\begin{abstract}
Manufacturing sector was one of the main drivers of economic growth at ASEAN and it is expected to expand. Although ASEAN is said to be the monetary area with various types of financial improvements and experiencing financial development, majority of the ASEAN countries are classified as a lower centre wage nation. The study uses the non-linear time varying factor approach on finding structural convergence of value added of manufacturing sectors in ASEAN. Alternatively, if the result shows there are convergence among the country, it could be an indicator of possible deeper economic integration and perhaps feasibility of monetary union. Countries that converges with other countries show that the ability of its to catch up with the higher one despite having different magnitude to converge. As stated in the ASEAN Economic Community (AEC), as a member the country must have the equitable of its economic growth and full integrated region in the global economic. The results indicate that there is no structural convergence in manufacturing sector in ASEAN, however, there are subgroup that converges to three club convergence with core group consist of Philippines and Singapore. The study concludes that manufacturing sector in ASEAN experiences strong similarity in its manufacturing sector and better prospect for convergence in the future.
\end{abstract}

Keyword: Manufacturing Convergence, Non-Linear Factor Model, Transition Path

\section{Introduction}

ASEAN has encountered the high financial development for a couple of decades in monetary exercises, for example, producing area, mining part, development division and horticulture segment. Yet, at that point, the areas are expanding and having changed commitment to GDP since there are numerous difficulties that organizations must face. For instance, its division has confronted an expanding in return rates, expansion, monetary standards, and decrease in resource cost. It's thoroughly influencing the financial segments through their sources of info, assets, capitals, exchanges and imports sends out in every nation. In any case, financial coordination could consolidate to create chances to ASEAN nations. It could likewise make challenges, to be specific 
higher costs identified with executing monetary combination over such as financial and social assorted variety nations. ASEAN is a monetary area, which has various types of financial improvement. Each nation has their methodologies and example to keep their nation ascend and creating. Besides, the vast majority of the ASEAN countries are classified as lower centre wage nations, though a couple are set in a superior economy. In this way, the current wage had a disparity hole between a portion of the ASEAN nations may wind up addressing from nation that face the lower one even they had set up more extensive district ASEAN Economic Community reconciliation and have coordinated effort between each other. The ASEAN Economic Community (AEC) was built up on 31 December 2015. However, the full association of the AEC vision was exhibited in 2007 will take additional time. The ASEAN origination of what provincial joining implies are expansive. However, that does not mean it is exceeding. Furthermore, the AEC economies have all things considered become quicker than some other Asian economy has spared China since the beginning of the century. The principle goals of the AEC have fivefold. There is a grasp incorporation, intensity, upgrade network and sectoral collaboration, impartial results, and worldwide commitment. The AEC is following brief comment is coming to be known as the four flexibilities with regards to European incorporation, opportunity of development of products, capital, administrations and work. In spite of the fact that there are numerous preferences and accomplishment since the ASEAN built up, the nation advancement and monetary improvement are recognized among every nation. Every nation has fluctuation accomplishment and positions that influence their monetary improvement in their nation.

Figure 1: Manufacturing in ASEAN

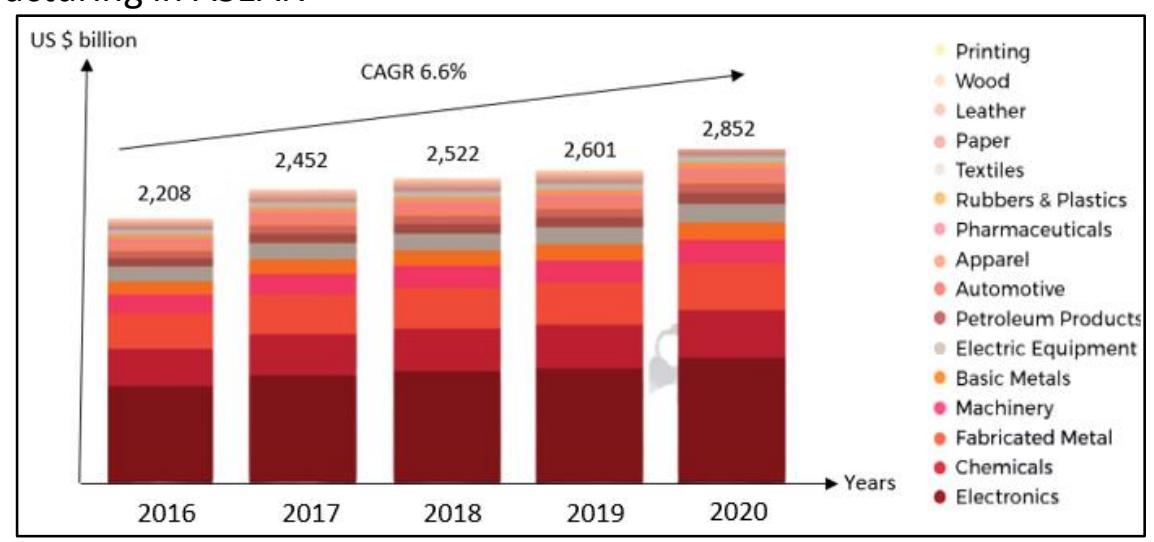

Source: Oxford Economics (2020)

Over the last decade, ASEAN has been growing its manufacturing output steadily and expanding its sector vastly, reporting a sturdy compound annual growth of $5.5 \%$ and accounting for $4 \%$ share of the global manufacturing output. The manufacturing sector was one of the main drivers of economic growth at ASEAN. The area is already a global manufacturing hub and is expected to expand between 2016 and 2020 at a compound annual growth rate (CAGR) of 6.6 per cent.

Major driver of demand in this sector is a 640 million strong region wide customer base with growing segment of middle income. Rising revenues which switch trends in consumption have also contributed to growth in this sector. In fact, the region's economies have low operating costs which 
attract businesses from larger production bases. Recently, China has experienced rising wages and tighter regulations which have resulted in increased operating costs as it shifts towards higher value production. Therefore, to replace Chin's once hold position, companies are looking to the ASEAN region for lower priced production networks that have also been largely integrated in to global value chains for manufacturing.

The participation of ASEAN in intraregional trade has strengthened its status as global hub for development such as the ASEAN Economic Community (AEC) envisages ASEAN as a framework for both single market and development.

In a nutshell, even though all the country in a same association such AEC, their economic growth and national income differs. The creation of $A E C$ is to achieve the same goals with the same strategies and plans, though one can stand by himself, alone. This is because their capability, skills, management, resources and technologies are varied each of the countries. So, does the lower country can catch up with the higher one as formed in the AEC?

\section{Literature Review}

Lie and Ahmad (2007) exhibit that the information creating procedure of wage differentials amongst Japan and all East Asian economies are nonlinear. Subsequently, the suitable testing technique within the sight of nonlinear pay differentials is by utilizing the nonlinear unit root test proposed by Kapetanios, Shin and Snell (2003; KSS, from this point forward). He discovered that 27 Korea, Hong Kong, and Taiwan and Singapore see merging with Japan. While China, Malaysia, Indonesia, Thailand and the Philippines showing dissimilarity. Then again, by adjusting the KSS test with the consideration of nonlinear pattern in the unit root testing strategy, the examination discovered that Hong Kong, Korea and Singapore are demonstrating long-run joining with Japan, while Taiwan is indicating making up for lost time with Japan.

Other than that, Zhang (2003) has been inspected whether East Asian economies can make up for lost time with Japan. He discovered that there is solid proof of the presence of different joining harmony over the ASEAN5, Korea, China, Hong Kong and Taiwan economies in the years 1960 to 1997. Zhang discovered two club merging which are rich club involving 28 Japan, Hong Kong, Malaysia, Singapore, Taiwan and Philippines. The poor club comprises of China, Korea, Indonesia and Thailand. Therefore, he utilized the model of nonlinear capacity to test for meeting between Korea, Japan and Taiwan for the period 1900s to 1992. Hsiao and Hsiao (2004) demonstrate that genuine GDP per capita of Taiwan and Korea are merging to that of Japan and the United States. Likewise, Japan's GDP per capita additionally meets to that of the United States.

Hway and Habibullah (2008); Parhoon et al (2014) inspected a proof of progressing genuine macroeconomic meeting of the establishing individuals from ASEAN to be specific, Indonesia, Malaysia, Singapore, Philippines and Thailand. They quantified utilizing genuine total national output (GDP) for the long run macroeconomics relationship towards ASEAN-5. At that point the progressing union of ASEAN-5 is inspected. The outcome demonstrates that the observational 29 discoveries recommend that there is for some time run macroeconomic linkages and the progressing meeting among ASEAN-5. Thus, ASEAN-5 is viewed as good, yet ASEAN endeavours of re-sorting out its supporting foundations will further improve the compatibility of their members. However, besides outstanding macroeconomic performance, there has a realization of a serious economic union would 
also depend on political stability and the sincerity of political leaders. On the other hand, Gouyette and Perelman (1997) expressed the productivity performances of 13 OECD countries' service and manufacturing sectors were estimated for the years 1970 to 1987 . They found that convergence is not found in the manufacturing sector, while convergence was found in productivity levels in the services sector. Muller (2000) studied the presence of sectoral convergence of labour productivity among 14 OECD countries. His study suggests that there is a strong sectoral convergence within most service sectors while the evidence of convergence for manufacturing as well as for communication sectors is rather weak. Affizzah (2011) also investigated the sectoral convergence between 15 OECD countries from 1970 to 1985 (ten sectors are distinguished) in a study on regional convergence in Euroland. The main finding in this study is that out of 10 sectors studied in term of their labor productivity, as many as seven of the ten sectors converged, confirming the claim that convergence is likely to be found in aggregate level rather than sectoral. A study by Bernard and Jones (1996) in examining the degree of sectoral convergence of six distinct sectors in the same 14 OECD countries reached the same conclusion. They stated that more evidence of converegnce can be found in aggregate level rather than sectoral level. Among all sectors, it is also revealed that labor productivity in service sectors shows higher magnitude of convergence whereas manufactung sectors foundto show the weakest rate of convrgence among OECD countries. Affizzah et al. (2009) investigated testing for convergence and catching up for Kedah with the other states in Malaysia. In Malaysia, the topic of economic convergence is much debated. Even though various Malaysia Development Plans proposed for the past three decades, regional differences among states persists. Therefore, the purpose of this research is to identify whether the state of Kedah has been converging, match or falling behind other states in Malaysia. They used the panel unit root test to run the result. The result obtained using the annual data for the years 1961-2003, propose that the state of Kedah has been catching-up with other states. Hence, the local government has an important role to play in enhancing the growth by continuously providing a stable economic environment for investment and other productive economic activities.

\section{The Non-linear Factor Model and Convergence}

Factor Analysis can produce a small number of factors from a large number of variables which is capable of explaining the observed variance in the larger number of variables.

Proposed equation may contain both common and idiosyncratic components in $g_{i t}$ and $a_{i t}$

$$
\mathrm{X}_{\mathrm{it}}=\frac{\text { git }+\mathrm{ait}}{\mu} \mu=\delta i t \mu t \text {, for all } i, t
$$

The setup proposed by Philips and Sul (2009) are able to separate the common and idiosyncratic components in the panel by factoring out the common stochastic trends component. $\mu$. Where $X$ is decomposed into two-time varying components; common, $\mathrm{t} \mu$ and idiosyncratic $\delta$. The components it $\delta$ is a measure of distance between its $\mathrm{X}$ and the common component, $\mathrm{t} \mu$. It absorbs the error term and the unit specific components and therefore represents the idiosyncratic part that is varying over time.

However, to specify the null hypothesis of convergence, the non-stationary transitional behaviour of factor loadings is proposed in semi parametric form, so that each coefficient converges to some unit specific constant:

$\delta_{\text {it }}=\delta_{\mathrm{i}}+\frac{\sigma i \varepsilon i t}{L(t) t \propto}$ 
Where $\delta_{\mathrm{i}}$ is fixed, $\varepsilon$ is iid $(0,1)$ across I s are idiosyncratic scale parameters, $\mathrm{L}(\mathrm{t})$ is a slowly varying function, $\mathrm{t} L(\mathrm{t})=\log$, so that $\mathrm{L}(\mathrm{t}) \rightarrow \infty$ as $t \rightarrow \infty$. The parameter a denotes the rate at which the crosssectional variation decays to zero. The formulation above ensures that $d_{i t} g_{i t}$ converges to $\delta$ for all $\alpha \geq 0$.

\section{Relative Transition Path}

A simple and practical way to extract information about dit is suggested by using its relative version as follow:

$\frac{\mathrm{X}_{\mathrm{it}}}{\frac{1}{N} \Sigma \frac{N}{i}=\text { Xit }}=\frac{\delta i t}{\frac{1}{N} \Sigma \frac{N}{i}}$

Based on Equation (4), states that in relation to panel average, dit is the measures of the factor loading coefficient. Meanwhile, $h_{i t}$, has the same function $d_{i t}$ which traces out transition path for the economy $i$, but now does so in relation to panel average. This will derive the transition path of the countries over time, in which hit, traces out an individual trajectory for each $i$ relative to the average. Based on the transiiton path $h_{i t}$, any divergence or an outlier from $\mu t$ can be revealed

In addition, hit as relative transition path will converge to unity with cross sectional variation of $\mathrm{Ht}$ converge to zero as panel unit converge and dit as factor loading approachFurthermore, if panel units converges and all the factor loading dit approach to a fixed $d$.

$H t=\frac{1}{N} \sum($ hit -1$) 2 N i=1 \rightarrow 0, t \rightarrow \infty$

The null hypothesis of convergence is tested by using properties as stated in equation 5 . Thus, the null hypothesis can now be specified as: $\mathrm{HO}: \delta i=\delta 0$ and $\alpha \geq 0$ for all i,against the alternative: $\mathrm{HA}: \delta i \neq \delta$ 0 for some $t$ and/or $\alpha<0$. The null hypothesis implies convergence for all countries, while the alternative hypothesis implies no convergence for some countries.

In this analysis, Hodrick and Prescott (1997) smoothing filter are adopted due to its strength ant it requires only the input of smoothing parameter. Furthermore there is prior requirement of the nature of the common trend $\mu \mathrm{t}$ in $\mathrm{X}_{\mathrm{it}}$. To extract the long run component $\delta i t \mu$ the filtering parameter is standardized equals to 100 for annual data. Thus, the estimated transition coefficient unit can be redeemed.

\section{Empirical Convergence Testing}

\section{The Log-t Regression}

The study applies convergence test and clustering algorithm based on the log t convergence test, introduced by Phillips and Sul (2007). The data gathered and run as simple time series regression. Yet, the unique thing about the test is it involves a one-sided t-test. The test is known as t-test as the t-statistic refers to the coefficient of log $t$ regression in the equation. In that framework, the null hypothesis is formulated as below:

$H$ : convergence for all i Ho: $\delta_{\mathrm{t}}$ and $\alpha>0$.

$H$ : No convergence for some $i \mathrm{H}_{\mathrm{A}} \delta_{\mathrm{t}} \neq \delta$ and $\alpha<0$

After estimating the transition path, the cross-sectional variation ratio of $\frac{\mathrm{Hi}}{\mathrm{Ht}}$ is to be computed by acknowledging $\mathrm{Ht}$ as:

$H t=\frac{1}{N} \sum(h i 1-1) N i=12$

Second, the following t regression is performed: 
$\log \left(\frac{H 1}{H t}\right)-2 \log L(t)=\hat{c}+b \log t+\mu \hat{t} \mathrm{t}=[\mathrm{rT}], \ldots \mathrm{T}$

Where $\mathrm{Ht}$ is the cross-sectional variation. $\left(\frac{H 1}{H T}\right)$ is the ratio of the cross-sectional variation at the beginning of the sample, $\mathrm{H} 1$ (i.e. $\mathrm{Ht}$ at $\mathrm{t}=1$ ) over the respective variation for every point in time $\mathrm{t}$, that is $\mathrm{Ht}(\mathrm{t}, \ldots, \mathrm{T})$. The ratio, $\left(\frac{\mathrm{H} 1}{\mathrm{Ht}}\right)$ measures the distance of the panel from the common limit. On the other hand, $L(t)=\log (t)$ and $r>0$. The regression presented in equation ( 8$)$ is called as log $t$ regression because of the log t regressor.

\section{The Club and Cluster}

Rejecting the null hypothesis that all sample countries converged doesn't not mean the absence of numerous convergence clubs within the group. Rejecting the null hypothesis does not rule out the possibility of convergence between clubs. In addition, there egression t-test can be used as the basis for a club convergence and clustering evaluation algorithm.

Based on the log t test by Phillips and Sul (2007), countries are allowed to achieve their own steady state of four steps:

1. Last order for observation: The first step in clustering is to rate the panel members according to the last observation. If several convergence clusters occur within the study, such as when $\mathrm{T} \rightarrow \infty$ is present, the panel is then clustered by two methods: using the last observation of the final Xit time series or using any final observation average. In this

2. Formation of Base Group: The highest rank of countries in sample will be chosen as base country. This is to form the subgroup Gk for some $N>k \geq 2$ and run the log $t$ regression and the convergence test statistic $t b(\mathrm{k})$ is calculated for each $\mathrm{k}$.Base or also known as core group size $k^{*}$ is chosen by maximizing tb, over $k$ according to the criteria of minimum $\{(k)\}>-1.65$. If the core group, $\mathrm{k}^{*}=\mathrm{N}$ thus there is only one large sample of panel convergent countries, no clusters and no individual divergent. Thus, convergence is exhibited in aggregate. Yet if the condition $\min \mathrm{tb},>-1.65$ does not hold for $\mathrm{k}=2$, then the first unit is drop and proceed with the same procedure for forming the next clusters.

3. Club Membership: The remaining unit is added separately to the core group after the core group has been established and the log t regression is performed for each addition

4. . Recursion and Stopping: The next cluster is form from these countries which fail to meet the condition in step 3 . The log t regression for the remaining countries is carried out for the remaining countries, i.e. to see if $t^{\wedge} b>-1.65$. If the null hypothesis is not rejected, thus these countries will form a second cluster. Again, the remaining countries will repeat step 1- to see if the group itself can be subdivided into convergence clusters. On the other hand, if there is no other sub group is found, and then these countries display a divergent behaviour.

\section{Empirical Results and Discussion}

Full Panel Convergence

In this section, the overall convergence test on the aggregate level is tested on the value added of manufacturing of ASEAN countries by applying the log t-test. There has a rejection rule in the result of panel convergence, if the t-statistic, $b$, is smaller than the critical value, -1.65 , the null hypothesis should be rejected. As stated by Philips \& Sul (2007), by applying an autocorrelation and a HAC 
INTERNATIONAL JOURNAL OF ACADEMIC RESEARCH IN BUSINESS AND SOCIAL SCIENCES

Vol. 11, No. 14, Contemporary Business and Humanities Landscape Towards Sustainability. 2021, E-ISSN: 2222-6990 @ 2021 HRMARS

standard error, at the $5 \%$ level, the null hypothesis of convergence is rejected when the t-statistic, $b$ $<-1.65$.

Table 1: Result of panel regression (Log t-test)

\begin{tabular}{|c|c|c|c|}
\hline Country & Sectors & $b$ & Remarks \\
\hline ASEAN Countries & Manufacturing & -7.135680 & Divergence \\
& & & \\
\hline
\end{tabular}

The result of panel convergence in manufacturing sector shows that the t-statistic is -7.135680 , which it is smaller than -1.65. So, the panel convergence was rejected the null hypothesis and it denotes as divergence for the period of 2008 till 2018. The result shows after the $30 \%$ of time series trimmed out. It was discarded because of as a satisfactory choice in term of both power and sizes. In addition, the divergence in the panel convergence is assumed that it is divergence for some countries in ASEAN, not at all are convergent (Affizah, 2011)

\section{Transition Path}

According to the Figure 1, it indicates the transition path of manufacturing sector in ASEAN countries. Transition path illustrate the trend of each country whether it can lead to unity or diverge among its members in the manufacturing sector. In this figure, it indicates that some of countries can be converging or vice versa. In particular, the Philippines and Singapore are converging since the slope for both are crossed. However, the slope that did not cross with other country does not mean it cannot converge, but it might be converge in the cluster of convergence in the subgroup.

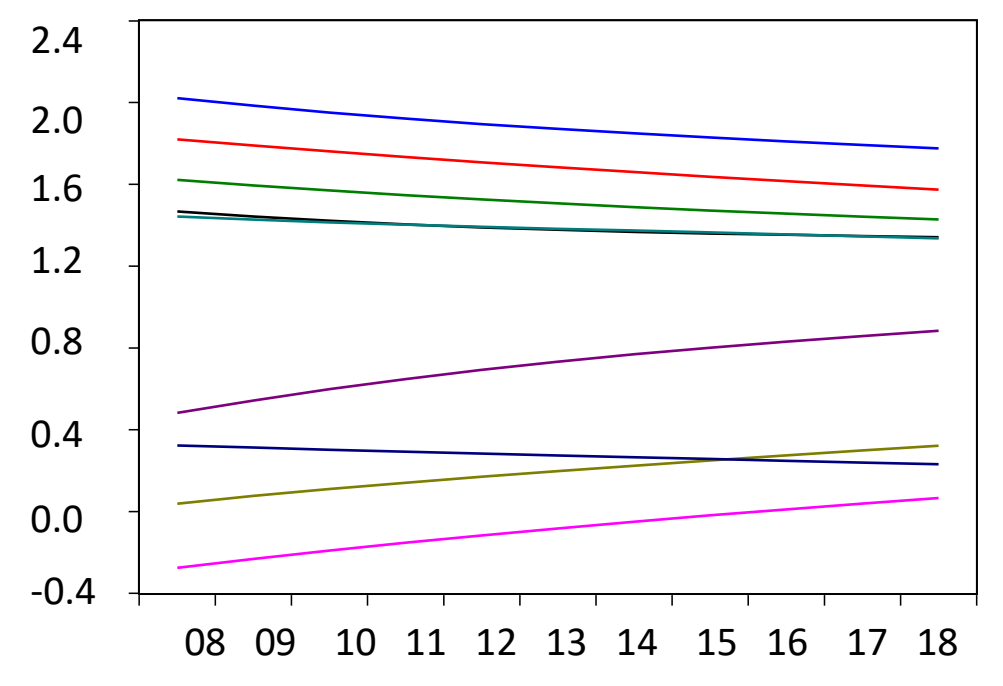




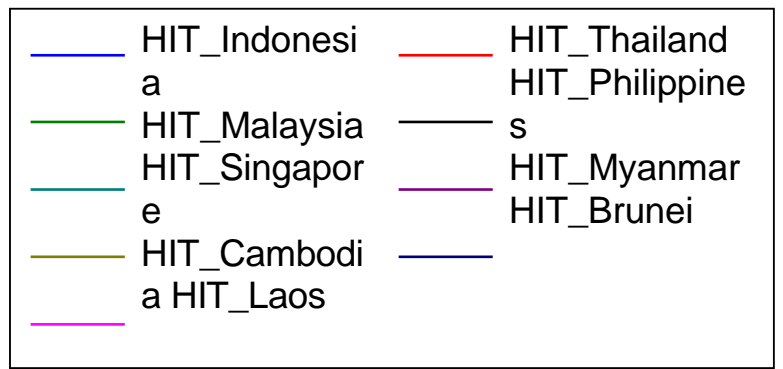

Figure 2: Transition path of manufacturing sector

\section{Convergence Club}

The results of club convergence in manufacturing sector in term of the value added by sector is shown in Table 1. The analysis on the manufacturing sector ASEAN has resulted three club's convergence. By having strong convergence within a group, it's a core club of convergence (Dyg-Affizzah, 2011). The manufacturing of ASEAN is cored by three countries, namely Malaysia, Philippines and Singapore. Despite of being small country, Singapore has continuously strengthened its manufacturing sector throughout the year. From 2014 to 2018, Singapore government has invested some $\$ \$ 500$ million to support the Future Manufacturing initiative. As in Malaysia and Philippines, the manufacturing sector is a key to contribute to the national income and the gross domestic product. These countries were grouped together, the manufacturing in Malaysia and Singapore seemed in the same stage while Philippines had a large amount of export in recent year. Even the Philippines is a low-income trap, however it can catch with Malaysia and Singapore as well. Turning back to ASEAN Economic Community $(A E C)$, one of the purposes of $A E C$ created is equitable economic development. Even though there are different region and country, but this club is to improve and collaborate each other to grow the economic development.

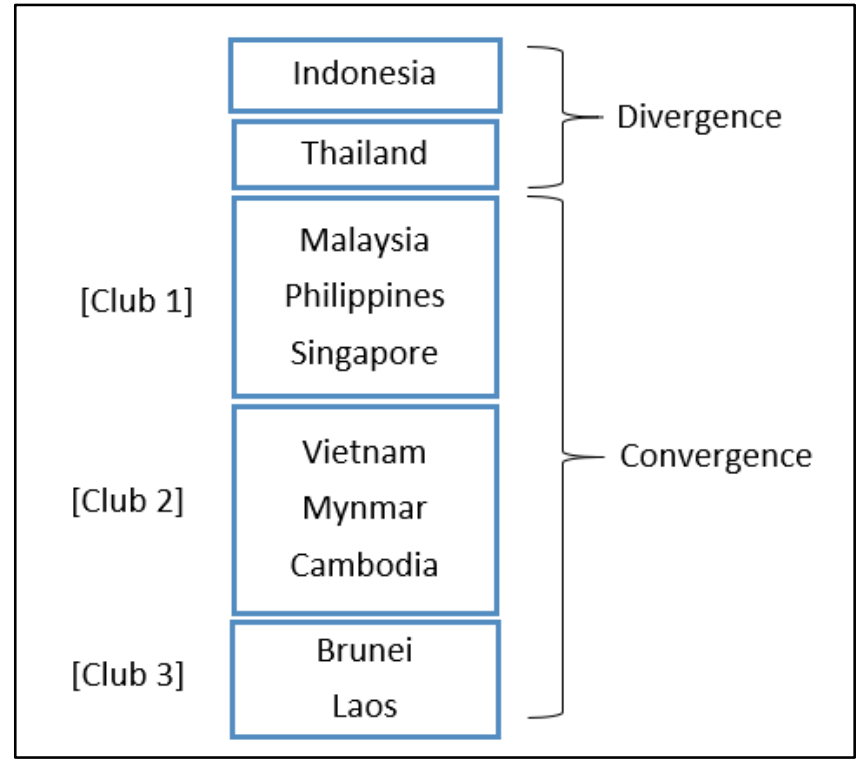

Figure 3: The results of club convergence in manufacturing sectors 


\section{Conclusion}

The government around the world is more concern about the inequality income between the lower income country and higher or advanced country. Even the vision of ASEAN is to cooperate in economic, promoting the political and security, the development of the country is diverse due to country growth itself and characteristics that the country have. The results show there is no structural convergence in ASEAN manufacturing sector. However, the club's convergence in the manufacturing sectors does exist indicating different level of manufacturing progress and development in ASEAN.

According to the result of manufacturing sector, there are three clubs of convergence exists in this sector in which it converges among the member which indicates a good sign since the AEC purpose is to cooperate in the economic development. Moreover, the manufacturing sector is the main economic activity that generates the national income in the country.

Most of the ASEAN countries have the tendency for economic integration by assessing its manufacturing industry and could catch up each other even there has different economic background. Even there are some countries that did not converge, it does not mean the country does not progress well. Perhaps it can be contradict interpreted, as peak development path as compared to the rest which is converging among another.

Since the establishment of AEC, the economic among the ASEAN members indicates the positive and growth in the development. As a member, they must to be collaborates and help each other such as supporting the members' trade and investing in term of economic development to that particular country and also has an equitable economic development. With all affords and cooperation, very soon the ASEAN countries will achieve their objectives in the ASEAN Economic Community.

\section{References}

Bernard, A. B., \& Jones, C. I. (1996). Comparing Apples to Oranges: Productivity Convergence and Measurement Across Industries and Countries. American Economics Review. Retrieved from https://pubs.aeaweb.org/doi/pdfplus/10.1257/aer.91.4.1168.

Marikan, D. A. A. (2011). Empirical Studies of Convergence in Income, Productivity and Competitiveness: The Experience of Asian Economies. University of Southampton Research Repository. Retrieved from https://eprints.soton.ac.uk/192733/1/A.M.DAYANG_AF ZZAH_final_submssion_hard_copy.pdf.

Dollar, D., Wolff, E. N., Wolff, E. N., \& Wolff, P. O. (1993). Competitiveness, Convergence, and International Specialization. MIT Press.

Hodrick, R. J., \& Prescott, E. C. (1997). Postwar US Business Cycle: An Empirical Investigation. Journal of Money, Credit and Banking. Retrieved from https://www.jstor.org/stable/2953682?seq=1.

Parhoon, K., Parhoon, H., \& Movallali, G. (2014). Effectiveness of Training Sensory Stimulation on Gross Motor Skills of 5-7 Years Old Children with Down Syndrome. International Journal of Academic Research in Psychology, 1(1), 22-31

Philips, P. C., \& Sul, D. (2009). Economic Transition and Growth. Journal of Applied Econometric, 24(7), 1153-1185. Retrieved from https://doi.org/10.1002/jae.1080.

Ong, H. B. \& Habibullah, M. S. (2008). Research Gate. Evidence of ongoing convergence. Int. Journal of Economics and Management 2(1): $127-140$ 
Lim, L. K., \& McAleer, M. (2006). Convergence and catching up in ASEAN: a comparative analysis, Journal Applied Economics, 2(36), 137-153

Oxford Economics. (2020). Economics forecast and reports. Retrieved from https://www.oxfordeconomics.com.

Stephen, M. M. (2000). Explaining Economic Growth: Factor Accumulation, Total Factor Productivity Growth, and Production Efficiency Improvement. Economics Working Papers. 200420. 